\title{
Heterogeneous ozonation of suspended malathion and chlorpyrifos particles
}

\author{
Junwang Meng, Bo Yang, Yang Zhang, Xinyu Dong, Jinian Shu * \\ Research Center for Eco-Environmental Sciences, Chinese Academy of Sciences, Beijing 100085, China
}

\section{A R T I C L E I N F O}

\section{Article history:}

Received 25 August 2009

Received in revised form 3 February 2010

Accepted 3 February 2010

Available online 21 February 2010

\section{Keywords:}

Pesticide

Ozonation

Malathion

Chlorpyrifos

Aerosol

AMS

\begin{abstract}
A B S T R A C T
The heterogeneous ozonation of suspended malathion and chlorpyrifos particles are studied in real-time with a vacuum ultraviolet photoionization aerosol time-of-flight mass spectrometer (VUV-ATOFMS). The pesticide particles with the diameter of hundreds of nanometers are generated by the homogeneous nucleation method using azelaic acid as nucleus. The reactions are carried out in an aerosol reaction chamber under ambient pressure ( $1 \mathrm{~atm}$ ) and room temperature ( $298 \mathrm{~K})$, respectively. The time-of-flight mass spectra of the solid-state ozonation products of malathion and chlorpyrifos are obtained. The assignments of the mass spectra reveal that the major ozonation products of malathion particles are s(1,2-diethoxycarbonyl)ethyl-0,0-dimethylphosphorothioate (malaoxon), 2-mercapto-succinic acid diethylester, 1,2-dicarbethoxyethyl-dimethoxyphosphinyldisulfide and bis(1,2-bis-ethoxycarbonylethyl)disulfide. The experimental results reveal that water vapor can enhance the formation of malaoxon, 2-mercapto-succinic acid diethylester and bis(1,2-bis-ethoxycarbonyl-ethyl)disulfide. In the case of chlorpyrifos, the sole ozonation product observed is 3,5,6-trichloro-2-pyridyl-diethylphosphate (chlorpyrifos oxon). The pathways of heterogeneous ozonation of malathion and chlorpyrifos particles are proposed. The atmospheric lifetimes of malathion and chlorpyrifos particles towards ozone reaction are estimated based on the time-dependent mass spectrometric signals obtained.
\end{abstract}

(c) 2010 Elsevier Ltd. All rights reserved.

\section{Introduction}

The wide use of organophosphorous pesticides has led to severe contamination of the environment. The atmosphere is considered as an important medium for dispersion of organophosphorus pesticides (Van Dijk and Guicherit, 1999; Van Pul et al., 1999). They can be released into atmosphere directly by spraying during application and indirectly via evaporization or soil erosion (Van den Berg et al., 1999; Gil and Sinfort, 2005; Luo and Zhang, 2009). The organophosphorus pesticides in the atmosphere exist in gasphase or adsorbed on atmospheric particles depending on their physicochemical properties (Atkinson et al., 1999; Bedos et al., 2002). Besides wet and dry deposition, the organophosphorus pesticides can be removed via reactions with nitrate radicals $\left(\mathrm{NO}_{3}\right)$, hydroxyl radicals $(\mathrm{OH})$ and ozone, as well as the direct photolysis during the atmospheric transport (Atkinson et al., 1999; Sabljic and Peijnenburg, 2001). These chemical conversions strongly affect the toxic properties and transport distances of the organophosphorus pesticides in the atmosphere (Van Pul et al., 1999). However, data on their atmospheric fate especially in the particle phase are limited (Atkinson et al., 1999).

Malathion and chlorpyrifos are two widely used organophosphorus pesticides. Both of them are toxic to humans. Exposure to

\footnotetext{
* Corresponding author. Tel.: +86 0106284 9508; fax: +86 01062923563

E-mail address: jshu@rcees.ac.cn (J. Shu).
}

them could lead to acute cholinergic poisoning and affect the central nervous system (Jamal, 1997). In the environment, the thiophosphoryl bonds $(\mathrm{P}=\mathrm{S})$ of malathion and chlorpyrifos can be oxidized to their corresponding $(\mathrm{P}=\mathrm{O})$ oxons by various oxidizing agents such as ozone, dinitrogen tetroxide, peracid and chlorine (Berkelhammer et al., 1963; Bellet and Casida, 1974; Ohashi et al., 1994; FinlaysonPitts and Pitts, 1997; Duirk et al., 2008). Chlorpyrifos oxon, the transformation product of chlorpyrifos, has been detected in the atmosphere (Aston and Seiber, 1997; LeNoir et al., 1999; Goel et al., 2007). The corresponding oxons are substantially more toxic, typically more potent in inhibition of acetylcholinesterase (AChE) than their parent compounds (Ryan and Fukuto, 1985; Wu and Laird, 2003; Kralj et al., 2007). There are extensive studies on the oxidation of malathion and chlorpyrifos in the soil and water (Mulla et al., 1981; Miles and Takashima, 1991; Racke, 1993). Besides oxidation, the hydrolysis reaction can also take place during the degradation of malathion and chlorpyrifos and play an important role in their degradation in soil (Mulla et al., 1981; Miles and Takashima, 1991; Racke, 1993) and water (Mulla et al., 1981; Liu et al., 2001; Pehkonen and Zhang, 2002; Duirk et al., 2008). In the atmosphere, gas-phase malathion can be oxidized to malaoxon by atmospheric oxidants such as ozone, nitrate radicals and $\mathrm{OH}$ radicals (Brown et al., 1993). Malathion and chlorpyrifos can also be found in the particle phase in the atmosphere (Vincent et al., 1997; Van Dijk and Guicherit, 1999) due to their low vapor pressures $\left(1.78 \times 10^{-4}\right.$ Pa for malathion 
and $2.5 \times 10^{-3} \mathrm{~Pa}$ for chlorpyrifos at $25^{\circ} \mathrm{C}$, respectively (Tomlin, 2006)). However, no data on the oxidation of malathion and chlorpyrifos particles in the atmosphere are available.

Ozone is one of the most common atmospheric oxidants and plays an important role in the chemistry of the atmosphere (Adeniji et al., 1981). The annual average background ozone concentrations over the midlatitude of the Northern Hemisphere range between $20 \mathrm{ppb}$ and $45 \mathrm{ppb}$ (Vingarzan, 2004) and it is present during day and night. Ozone can react with many organic compounds, such as unsaturated hydrocarbons, aromatics and sulfurcontaining organics in the atmosphere (Atkinson and Carter, 1984; Ljubic and Sabljic, 2002).

In this paper, the heterogeneous ozonation of suspended malathion and chlorpyrifos particles by gaseous ozone is investigated utilizing a vacuum ultraviolet photoionization aerosol time-offlight mass spectrometer (VUV-ATOFMS) under the pseudo-firstorder conditions in an aerosol reaction chamber. The VUV-ATOFMS is an instrument developed for analyzing the chemical composition of suspended organic particles on-line (Shu et al., 2008). Combing with gas chromatography, the electron-impact mass spectrometer is used to identify organics. However, the mass spectra of complex organic aerosols obtained with aerosol mass spectrometer equipped with an electron-impact ionizer are usually too complicate to identify organics. Utilizing a VUV photoionization source, the VUV-ATOFMS is capable of acquiring mass spectra of organic particles with less fragments or even fragment free, which are easier to assign than the ones obtained with an electron-impact source (Shu et al., 2008; Gao et al., 2009). The real-time analysis of the solid-state products is conducted and reaction products are speculated based on the mass spectra obtained. The pathways of heterogeneous ozonation of malathion and chlorpyrifos particles are proposed in the paper.

\section{Experimental}

The experimental setup has been described in detail elsewhere (Gao et al., 2009; Meng et al., 2009). Briefly, the aerosol reaction chamber consists of a thin-walled open head stainless steel drum $(50 \mathrm{~cm}$ (outer diameter) $\times 60 \mathrm{~cm}$ (height)) and a thin Tedlar polyvinyl fluoride (PVF) film bag $(50 \mathrm{~cm}$ (diameter) $\times 50 \mathrm{~cm}$ (length)). The volume of the reaction chamber is $\sim 200 \mathrm{~L}$ when the film bag is fully filled. A small fan is set at the bottom of the aerosol reaction chamber to mix the reactants quickly. Prior to each experiment, the reaction chamber is rinsed with ethanol, dried with hot air and then filled with filtered air. The relative humidity in the chamber is estimated to be $\sim 5 \%$ due to the residual filtered ambient air in the chamber. The size distribution of the particles is measured with a scanning mobility particle sizer (SMPS) composed of a differential mobility analyzer (DMA, TSI model 3081) and a condensation particle counter (CPC, TSI model 3776). Ozone is generated with an ozone generator (NIPPON, model NPF8W). Pure $\mathrm{O}_{2}$ $(99.99 \%)$ is used as discharging gas. The flow of discharging gas is maintained at $5 \mathrm{~L} \mathrm{~min}^{-1}$. The concentration of ozone in the reaction chamber is controlled by adjusting the feed-in time of the discharged gas and detected with an ozone monitor (2B technologies Inc., model $201 \mathrm{M}$ ). The VUV-ATOFMS used to analyze the malathion, chlorpyrifos and their ozonation products is home-built. Its detailed description has been given elsewhere (Shu et al., 2008). Only information directly related to the present work is described here. The sample rate of the VUV-ATOFMS is $1.3 \mathrm{~cm}^{3} \mathrm{~s}^{-1}$. An $8 \mathrm{~mm}$ diameter copper rod coupled to a cartridge heater driven by a DC power supply is used to vaporize organic particles. The heater temperature is $\sim 400 \mathrm{~K}$. The vapor generated from particles is photoionized with light radiated from a home-assembled RF-powered VUV lamp. Then, the ions produced by VUV photoionization are de- tected with a reflectron mass spectrometer. The reflectron mass spectrometer is characterized with a field-free flight distance of $1.4 \mathrm{~m}$, an ion mirror and a chevron multichannel plate detector.

The suspended malathion or chlorpyrifos particles with azelaic acid as nucleus are generated by the homogeneous nucleation method. The aerosol generator consists of two tandem $3 \mathrm{~cm}$ (outer diameter) $\times 40 \mathrm{~cm}$ (length) quartz tubes equipped with heating tapes and thermometers. About $0.2 \mathrm{~g}$ azelaic acid used to generate nucleus is put in a small boat-shaped ceramic container positioned at the center of the first quartz tube. Azelaic acid is chosen as the nucleus because it has little reactivity with ozone (Kwamena et al., 2007). The temperature of the first quartz tube is set at $413 \mathrm{~K}$. Fig. 1 shows the size distributions of the azelaic acid particles (line with open circles) in the aerosol reaction chamber after $\sim 20$ min filling. Meanwhile, $\sim 0.1 \mathrm{~g}$ malathion or chlorpyrifos used to coat the azelaic acid nucleus is placed into the center of the second quartz tube. The temperature of the second tube is set at $358 \mathrm{~K}$ for malathion and $385 \mathrm{~K}$ for chlorpyrifos, respectively. The particle concentration and coating thickness are controlled by adjusting the temperature of the quartz tubes during the experiments. Pure nitrogen passes through the two tubes sequentially at a volumetric flow of $\sim 0.5 \mathrm{~L} \mathrm{~min}^{-1}$. The temperature of each quartz tube is optimized to produce particles with expected size and mass concentration to meet the detection limit of the VUV-ATOFMS. Fig. 1 shows the size distributions of the malathion (line with triangles) and chlorpyrifos (line with closed circles) coated azelaic acid particles in the aerosol reaction chamber measured with SMPS before the ozone injection. The size distribution of the pure azelaic acid particles has a mean diameter of $148 \mathrm{~nm}$ and the mass concentration of azelaic acid particles is $\sim 779 \mu \mathrm{g} \mathrm{m}^{-3}$. The density of azelaic acid is $1.2 \mathrm{~g} \mathrm{~cm}^{-3}$ (Lide and Milne, 1994). The size distributions of the malathion and chlorpyrifos coated particles shift to the mean diameters of $216 \mathrm{~nm}$ and $376 \mathrm{~nm}$. The mass concentrations of malathion and chlorpyrifos coated particles are $\sim 1308 \mu \mathrm{g} \mathrm{m}^{-3}$ and $\sim 2744 \mu_{\mathrm{g} \mathrm{m}}^{-3}$ respectively. The densities of malathion and chlorpyrifos are $1.2 \mathrm{~g} \mathrm{~cm}^{-3}$ and $1.4 \mathrm{~g} \mathrm{~cm}^{-3}$ (Tomlin, 2003), respectively. On the assumption that the azelaic acid core is spheric and the pesticide coating is uniform, the masses of particulate malathion and chlorpyrifos are estimated roughly at $\sim 179 \mu \mathrm{g}$ and $521 \mu \mathrm{g}$ in the $\sim 200 \mathrm{~L}$ reaction chamber. The masses of saturated malathion and chlorpyrifos vapor in the reaction chamber are estimated at $\sim 4.7 \mu \mathrm{g}$ and $\sim 70.5 \mu \mathrm{g}$ according the pesticide vapors mentioned above and the equation $P V=n R T$. This ensures that the concentra-

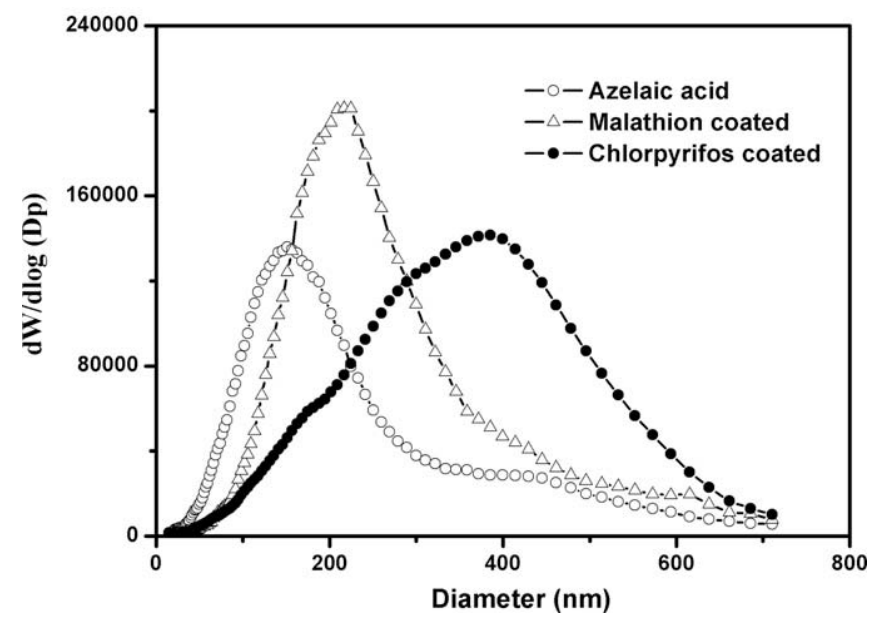

Fig. 1. Particle size distributions of azelaic acid (line with open circles), malathion (line with triangles), and chlorpyrifos (line with closed circles) particles measured by SMPS. 
tion of particulate pesticides in the reaction chamber is higher compared to corresponding concentrations in the gas-phase.

Chlorpyrifos ( 99.5\%, Dikma Inc. Beijing), malathion ( 99.5\%, Dikma Inc. Beijing), azelaic acid (99\%, China North Region Special Chemical Reagent Development Center), oxygen (99.99\%, Beijing Huayuan Gas Chemical Industry Co. Ltd.) and nitrogen (99.99\%, Beijing Huayuan Gas Chemical Industry Co. Ltd.) are used in the experiment.

\section{Results and discussion}

The time-of-flight mass spectrum of malathion particles and the molecular structure of malathion $\left(\mathrm{C}_{10} \mathrm{H}_{19} \mathrm{O}_{6} \mathrm{PS}_{2}\right.$, mol. wt. $\left.330 \mathrm{Da}\right)$ are shown in Fig. 2A. The mass spectrum of malathion particles is acquired before ozone is injected into the reaction chamber. The acquisition time for the mass spectrum is $30 \mathrm{~s}$. The prominent mass peak is at $m / z$ 173. The intensities of all the mass peaks are normalized to the mass peak at 173 . The mass peak at $m / z 330$ is assigned to the molecular ion of malathion. The mass peaks at $m /$

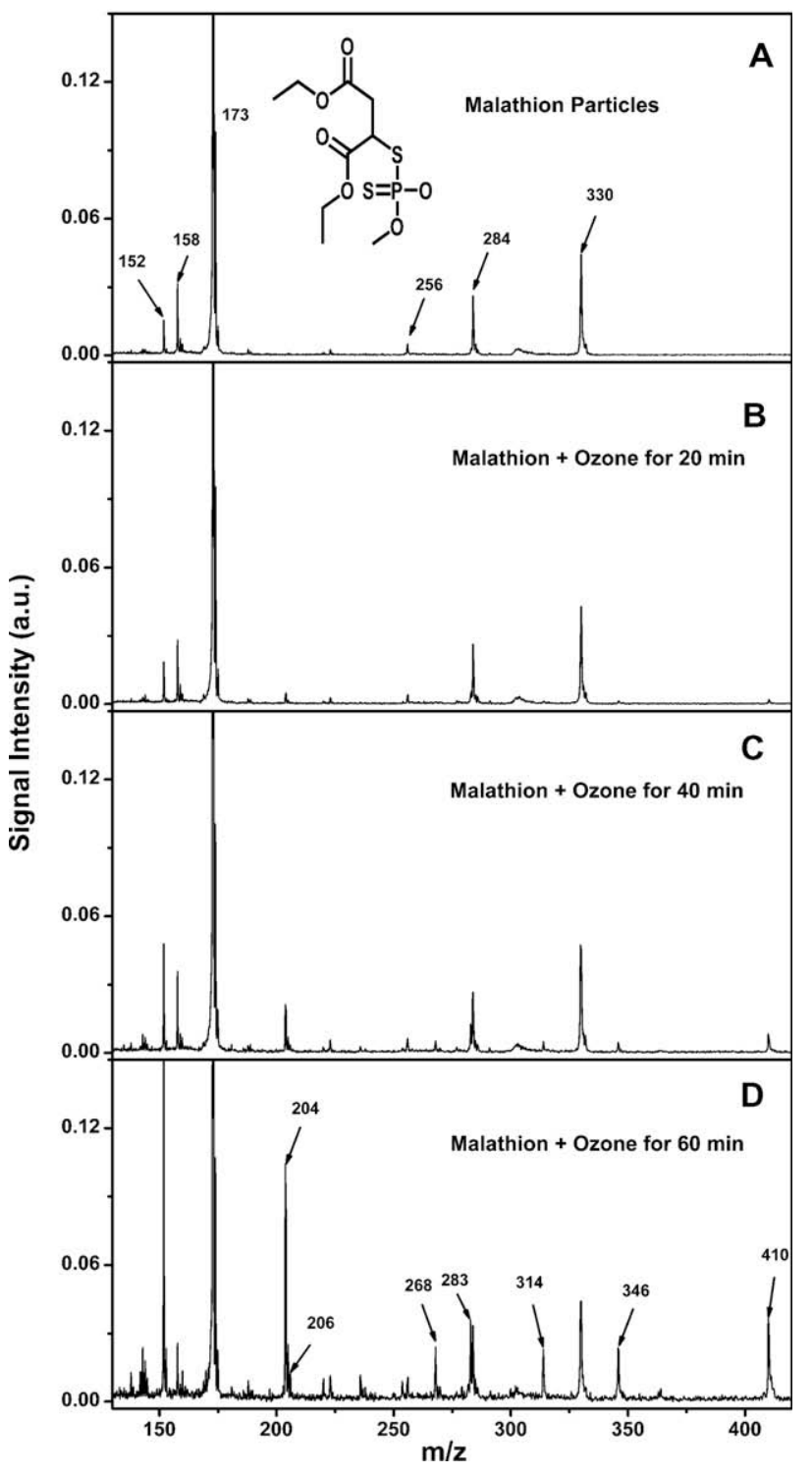

Fig. 2. (A) TOF mass spectrum of malathion particles, (B-D) TOF mass spectra of the ozonation products of malathion particles acquired 20,40 and 60 min after the ozone injection. The acquisition time for each mass spectrum is $30 \mathrm{~s}$. The intensities of all mass peaks are normalized to the mass peak at $m / z 173$.
Table 1

The intensities and assignments of the mass peaks of malathion and its ozonation products. The symbol $\eta$ stands for the relative intensities of the mass peaks shown in Figs. 2A, 3A and 3B.

\begin{tabular}{lllll}
\hline$m / z$ & Ions & \multicolumn{3}{l}{$\eta$} \\
\cline { 3 - 5 } & & Malathion $^{\mathrm{a}}$ & Products $^{\mathrm{b}}$ & Products $^{\mathrm{c}}$ \\
\hline 410 & $\mathrm{C}_{16} \mathrm{H}_{26} \mathrm{O}_{8} \mathrm{~S}_{2}^{+}$ & & 0.008 & 0.016 \\
346 & $\mathrm{C}_{10} \mathrm{H}_{19} \mathrm{O}_{7} \mathrm{PS}_{2}^{+}$ & & 0.004 & 0.005 \\
330 & $\mathrm{C}_{10} \mathrm{H}_{19} \mathrm{O}_{6} \mathrm{PS}_{2}^{+}$ & 0.046 & & \\
314 & $\mathrm{C}_{10} \mathrm{H}_{19} \mathrm{O}_{7} \mathrm{PS}^{+}$ & & 0.007 & 0.020 \\
284 & $\mathrm{C}_{8} \mathrm{H}_{13} \mathrm{O}_{5} \mathrm{PS}_{2}^{+}$ & 0.026 & & \\
268 & $\mathrm{C}_{8} \mathrm{H}_{13} \mathrm{O}_{6} \mathrm{PS}^{+}$ & & 0.008 & 0.016 \\
256 & $\mathrm{C}_{7} \mathrm{H}_{1} 3 \mathrm{O}_{4} \mathrm{PS}_{2}^{+}$ & 0.005 & & 0.021 \\
204 & $\mathrm{C}_{8} \mathrm{H}_{12} \mathrm{O}_{4} \mathrm{~S}^{+}$ & & 0.015 & \\
173 & $\mathrm{C}_{8} \mathrm{H}_{13} \mathrm{O}_{4}^{+}$ & 1.000 & & \\
158 & $\mathrm{C}_{2} \mathrm{H}_{7} \mathrm{O}_{2} \mathrm{PS}_{2}^{+}$ & 0.031 & & \\
\hline
\end{tabular}

All of the peak intensities are normalized to the mass peak at $m / z 173$.

a Mass peaks in Fig. 2A.

b Mass peaks in Fig. 3A.

c Mass peaks in Fig. 3B.

$z 158,173,256$ and 284 are assigned to the daughter ions of malathion $\mathrm{C}_{2} \mathrm{H}_{7} \mathrm{O}_{2} \mathrm{PS}_{2}^{+}, \mathrm{C}_{8} \mathrm{H}_{13} \mathrm{O}_{4}^{+}, \mathrm{C}_{7} \mathrm{H}_{13} \mathrm{O}_{4} \mathrm{PS}_{2}^{+}$and $\mathrm{C}_{8} \mathrm{H}_{13} \mathrm{O}_{5} \mathrm{PS}_{2}^{+}$. The ion $\mathrm{C}_{8} \mathrm{H}_{13} \mathrm{O}_{4}^{+}(\mathrm{m} / \mathrm{z} 173)$ results from the simple cleavage of the $\mathrm{C}-\mathrm{S}$ bond of malathion during the VUV photoionization. Malathion loses 2-butenedioic acid $(\mathrm{Z})$-, diethyl ester $\left(\mathrm{C}_{8} \mathrm{H}_{12} \mathrm{O}_{4}\right)$, formic acid, ethyl ester $\left(\mathrm{C}_{3} \mathrm{H}_{6} \mathrm{O}_{2}\right)$ and ethanol $\left(\mathrm{C}_{2} \mathrm{H}_{6} \mathrm{O}\right)$ forming $\mathrm{C}_{2} \mathrm{H}_{7} \mathrm{O}_{2} \mathrm{PS}_{2}^{+}(\mathrm{m} /$ $z$ 158), $\mathrm{C}_{7} \mathrm{H}_{13} \mathrm{O}_{4} \mathrm{PS}_{2}^{+}\left(\mathrm{m} / z\right.$ 256) and $\mathrm{C}_{8} \mathrm{H}_{13} \mathrm{O}_{5} \mathrm{PS}_{2}^{+}(\mathrm{m} / \mathrm{z} 284)$ during the VUV photoionization, respectively. The small mass peaks at $\mathrm{m} / \mathrm{z} 220$ and 223 (Fig. 2) are the background noise of VUV-ATOFMS which appears during the experiments. The mass peak at $m / z 152$ is contributed from the azelaic acid nucleus and is not discussed in the paper. The tentative assignments of the mass peaks discussed above are listed in Table 1.

The time-of-flight mass spectra of solid-state ozonation products of malathion particles are shown in Fig. 2B-D, which are acquired 20, 40 and $60 \mathrm{~min}$ after ozone is injected into the reaction chamber. The acquisition time for each spectrum is $30 \mathrm{~s}$. Each spectrum is normalized with the intensity of the mass peak at $m / z 173$. The initial concentration of ozone is $\sim 95 \mathrm{ppm}\left(2.6 \times 10^{15}\right.$ molecule $\mathrm{cm}^{-3}$ ). The main mass peaks of the ozonation products of malathion particles located at $m / z 204,206,268,314,346$ and 410 arise 20 min after ozone is injected into the reaction chamber (Fig. 2B). The intensities of the mass peaks of the ozonation products increase with the reaction time. The mass peaks at $\mathrm{m} / \mathrm{z}$ 314 and 346 are assigned to malaoxon $\left(\mathrm{C}_{10} \mathrm{H}_{19} \mathrm{O}_{7} \mathrm{PS}\right.$, mol. wt. $314 \mathrm{Da}$ ) and 1,2-dicarbethoxyethyl-dimethoxyphosphinyldisulfide $\left(\mathrm{C}_{10} \mathrm{H}_{19} \mathrm{O}_{7} \mathrm{PS}_{2}\right.$, mol. wt. $\left.346 \mathrm{Da}\right)$, respectively. Malaoxon and 1,2dicarbethoxyethyl-dimethoxyphosphinyldisulfide were reported as products of oxidation of malathion by Bellet and Casida (1974). Miyamoto and Yamamoto (1977) also reported the similar analogues from the oxidation of O,O-diethyl-s-(4-chlorophenyl)phosphorodithioate. Malaoxon, the main oxidation product of malathion, was observed in the ozonation and the degradation of malathion in water and soil (Laplanche et al., 1984; Reynolds et al., 1989; Miles and Takashima, 1991; Bavcon et al., 2003; Ikehata and El-Din, 2005; Bavcon Kralj et al., 2007; Zhao and Hwang, 2009). The mass peak at $m / z 268$ is assigned to $\mathrm{C}_{8} \mathrm{H}_{13} \mathrm{O}_{6} \mathrm{PS}^{+}$, the malaoxon daughter ion after losing ethanol $\left(\mathrm{C}_{2} \mathrm{H}_{6} \mathrm{O}\right)$ group during the VUV photoionization. The mass peaks at $m / z 204$ and 410 are tentatively assigned to 2-mercapto-succinic acid diethylester $\left(\mathrm{C}_{8} \mathrm{H}_{14} \mathrm{O}_{4} \mathrm{~S}\right.$, mol. wt. $\left.206 \mathrm{Da}\right)$ and bis(1,2-bis-ethoxycarbonylethyl)disulfide $\left(\mathrm{C}_{16} \mathrm{H}_{26} \mathrm{O}_{8} \mathrm{~S}_{2}\right.$, mol. wt. $\left.410 \mathrm{Da}\right)$, respectively. 2-Mercapto-succinic acid diethylester may form $\mathrm{C}_{8} \mathrm{H}_{12} \mathrm{O}_{4} \mathrm{~S}^{+}(\mathrm{m} / z$ 204) by losing one hydrogen molecule during the VUV photoionization. There is also a minor mass peak at $m / z$ 206, which may be 
contributed from the molecular ion of 2-mercapto-succinic acid diethylester directly. 2-Mercapto-succinic acid diethylester was reported as an environmental transformation product of malathion (Brown et al., 1993). Bis(1,2-bis-ethoxycarbonyl-ethyl)disulfide may be produced by the oxidation of 2-mercapto-succinic acid diethylester, which is similar to the formation of bis(4-chlorophenyl)disulfide observed in the oxidation of 0,O-diethyl-s-(4chlorophenyl)phosphorodithioate (Miyamoto and Yamamoto, 1977). The minor mass peaks at $m / z$ 160, 188, 236, 254 and 283 cannot be assigned.

In order to evaluate the influence of water vapor on the heterogeneous ozonation of malathion particles, additional experiments are conducted under extremely dry ( $\mathrm{RH}<1 \%$ estimated) and wet ( $\mathrm{RH} \sim 80 \%$ measured) conditions. In the experiment with the extremely dry condition, nitrogen is used as the balance gas in the reaction chamber. The $\mathrm{RH}$ in the reaction chamber is estimated as $<1 \%$ under this condition. In the experiment with high $\mathrm{RH}$, the reaction chamber was injected with filtered water vapor and the $\mathrm{RH}$ in the reaction chamber is measured with a hygrometer. Fig. 3A and $3 \mathrm{~B}$ show the time-of-flight mass spectra of solid-state ozonation products of malathion particles obtained under $\mathrm{RH}<1 \%$ and $\mathrm{RH} \sim 80 \%$, respectively. The relative intensities of the mass peaks (Fig. 3) are listed in Table 1. Compared with Fig. 3A, the relative intensities of the mass peaks at $m / z 204,314$ and 410 shown in Fig. 3B are greatly enhanced under the extremely wet condition (Table 1). The relative intensities of mass peaks at $\mathrm{m} / \mathrm{z} 204,314$ and 410 are increased by $40 \%, 200 \%$ and $100 \%$ under the high $\mathrm{RH}$ condition, respectively. These experimental results show that water vapor have a strong influence on the ozonation of malathion particles.

The time-of-flight mass spectra of chlorpyrifos particles $\left(\mathrm{C}_{9} \mathrm{H}_{11} \mathrm{Cl}_{3} \mathrm{NO}_{3} \mathrm{PS}\right.$, mol. wt. $\left.349 \mathrm{Da}\right)$ and its ozonation products are shown in Fig. 4. The mass spectrum of chlorpyrifos particles shown in Fig. 4A is collected before ozone is injected into the reaction chamber. The initial concentration of ozone is $\sim 55 \mathrm{ppm}$ $\left(1.5 \times 10^{15}\right.$ molecule $\left.\mathrm{cm}^{-3}\right)$. The time-of-flight mass spectra of the chlorpyrifos ozonation products shown in Fig. 4B and 4C are collected 30 and $60 \mathrm{~min}$ after the ozone injection. The acquisition time for each mass spectrum is $30 \mathrm{~s}$ and each mass spectrum is

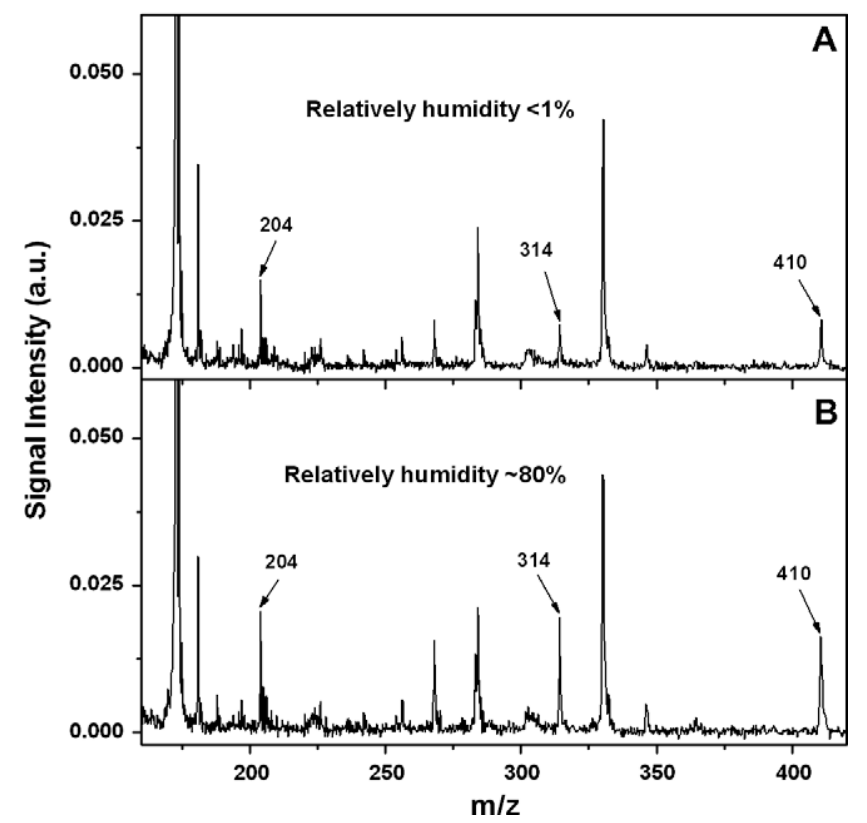

Fig. 3. TOF mass spectra of the ozonation products of malathion particles under low $(<1 \%)$ (A) and high ( $\sim 80 \%)$ (B) RH. The mass spectra are acquired 20 min after the ozone injection and the acquisition time for each mass spectrum is $30 \mathrm{~s}$. The intensities of all mass peaks are normalized to the mass peak at $m / z 173$.

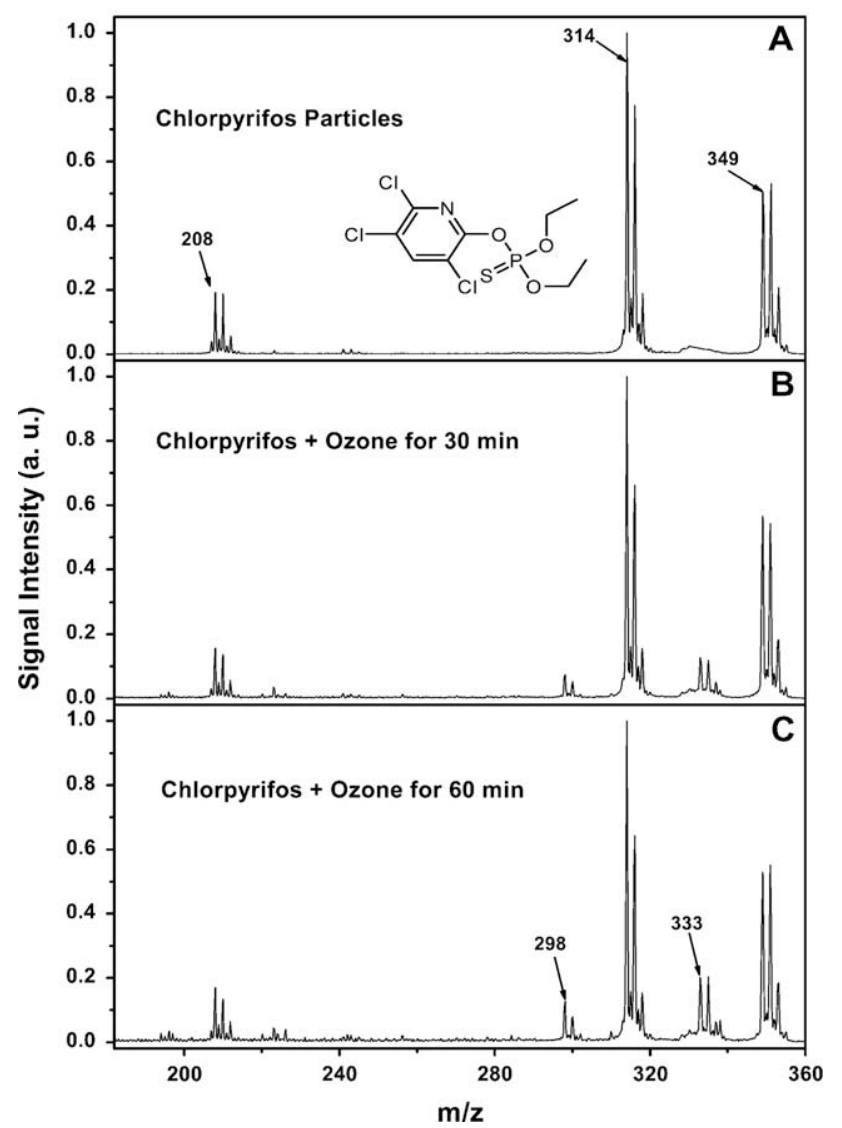

Fig. 4. (A) TOF mass spectra of chlorpyrifos particles, (B and C) TOF mass spectra of the ozonation products of chlorpyrifos particles acquired 30 and $60 \mathrm{~min}$ after the ozone injection. The acquisition time for each mass spectrum is $30 \mathrm{~s}$. The intensities of all mass peaks are normalized to the mass peak at $m / z 314$.

normalized to its most intense mass peak at $m / z$ 314. The mass spectrum of chlorpyrifos is composed of three clusters of mass peaks (Fig. 4A). The mass peaks at $m / z 349,351$ and 353 are from molecular ions of chlorpyrifos with ${ }^{35} \mathrm{Cl}_{3},{ }^{35} \mathrm{Cl}_{2}{ }^{37} \mathrm{Cl}$ and ${ }^{35} \mathrm{Cl}^{37} \mathrm{Cl}_{2}$, respectively. The mass peaks at 314,316 and 318 are assigned to the daughter ions of chlorpyrifos after losing a $\mathrm{Cl}$ atom during the VUV photoionization. The mass peaks at $m / z 208$ and 210 cannot be assigned. The new mass peaks at $m / z$ 298, 300, 333 and 335 shown in Fig. 4B and 4C arise after the ozone injection. Referring to the previous studies by Racke (1993), Glotfelty et al. (1987), Liu et al. (2001), Duirk et al. (2008) and Bellet and Casida (1974), the mass peak at $\mathrm{m} / \mathrm{z} 333$ is assigned to chlorpyrifos oxon $\left(\mathrm{C}_{9} \mathrm{H}_{11} \mathrm{Cl}_{3} \mathrm{NO}_{4} \mathrm{P}\right.$, mol. wt. $\left.333 \mathrm{Da}\right)$, which is regularly found as the transformation product of chlorpyrifos in the atmosphere (Glotfelty et al., 1987; Aston and Seiber, 1997; LeNoir et al., 1999). The mass peak at $\mathrm{m} / \mathrm{z} 335$ is contributed from chlorpyrifos oxon with one isotope ${ }^{37} \mathrm{Cl}$ atom. The mass peaks at $\mathrm{m} / z 298$ and 300 are assigned to the daughter ions of chlorpyrifos oxon after losing a $\mathrm{Cl}$ atom during the VUV photoionization. Besides chlorpyrifos oxon, a few of new weak mass peaks from $\mathrm{m} / \mathrm{z} 190$ to 290 arise during the ozonation of chlorpyrifos (Fig. 4C), which may be contributed from some minor products formed in the ozonation processes. The relative intensities and tentatively assignments of the mass peaks discussed are listed in Table 2 .

It has been reported that the m-chloroperoxybenzoic acid oxidation of thionophosphorus compounds is initiated by addition of oxygen to the $\mathrm{P}=\mathrm{S}$ moiety (Bellet and Casida, 1974), forming unstable phosphorus oxythionate intermediates with a cyclic $\mathrm{P}-\mathrm{S}-\mathrm{O}$ group. The unstable oxidized intermediates undergo the 
Table 2

The intensities and assignments of the mass peaks of chlorpyrifos and its ozonation products. The symbol $\eta$ stands for the intensities of the mass peaks shown in Fig. 4.

\begin{tabular}{llll}
\hline$m / z$ & Ions & $\eta$ & \\
\cline { 3 - 4 } & & Chlorpyrifos $^{\mathrm{a}}$ & Products $^{\mathrm{b}}$ \\
\hline 349 & $\mathrm{C}_{9} \mathrm{H}_{11} \mathrm{Cl}_{3} \mathrm{NO}_{3} \mathrm{PS}^{+}$ & 0.507 & \\
333 & $\mathrm{C}_{9} \mathrm{H}_{11} \mathrm{Cl}_{3} \mathrm{NO}_{4} \mathrm{P}^{+}$ & & 0.210 \\
314 & $\mathrm{C}_{9} \mathrm{H}_{11} \mathrm{Cl}_{2} \mathrm{NO}_{3} \mathrm{PS}^{+}$ & 1.000 & 0.128 \\
298 & $\mathrm{C}_{9} \mathrm{H}_{11} \mathrm{Cl}_{2} \mathrm{NO}_{4} \mathrm{P}^{+}$ & & 0.128 \\
\hline
\end{tabular}

All of the peak intensities are normalized to the mass peak at $m / z 314$.

a Mass peaks in Fig. 4A.

b Mass peaks in Fig. 4C.

rearrangement to form the stable products. The ozonation of malathion and chlorpyrifos may undergo the reaction pathways similar to the m-chloroperoxybenzoic acid oxidation of thionophosphorus compounds and the ozonation may be initiated by the attack of ozone on the $\mathrm{P}=\mathrm{S}$ double bond. Based on the assignments of the mass spectra above, the mechanisms for the heterogeneous ozonation of malathion and chlorpyrifos are proposed. Fig. 5 shows the pathways of the heterogeneous ozonation of malathion. The ozonation of malathion undergoes three different pathways. Pathway I is the loss of sulfur, which yields malaoxon. This pathway is also the common pathway of the oxidation of thionophosphorous compounds. Pathway II is the formation of 1,2-dicarbethoxyethyl-dimethoxyphosphinyldisulfide through the intramolecular rearrangement of atoms.

Pathway III of the malathion ozonation is hydrolysis of the unstable phosphorus oxythionate intermediates, which is suggested by the observation of the intense signals at $\mathrm{m} / \mathrm{z} 204$ and 410. The mass peak at $m / z 410$ is assigned to bis(1,2-bis-ethoxycarbonyl-ethyl)disulfide $\left(\mathrm{C}_{16} \mathrm{H}_{26} \mathrm{O}_{8} \mathrm{~S}_{2}\right.$, mol. wt. $\left.410 \mathrm{Da}\right)$. It has been reported that the disulfide can be formed from oxidation of thiols (Bellet and Casida, 1974; Miyamoto and Yamamoto, 1977). Therefore, we speculate that bis(1,2-bis-ethoxycarbonyl-ethyl)disulfide observed may be produced through the oxidation of 2-mercaptosuccinic acid diethylester $\left(\mathrm{C}_{8} \mathrm{H}_{14} \mathrm{O}_{4} \mathrm{~S}\right.$, mol. wt. $\left.206 \mathrm{Da}\right)$. A small mass peak at $\mathrm{m} / \mathrm{z} 206$ is observed, which may be attributed to the molecular ion of 2-mercapto-succinic acid diethylester. The intense mass peak at $m / z 204$ is tentatively assigned to the daughter ion of 2-mercapto-succinic acid diethylester after losing one hydrogen molecule during the VUV photoionization. Additionally, a small mass peak at $m / z 142$ is also observed, which can be assigned to $\mathrm{O}, \mathrm{O}^{\prime}$-dimethylphosphorothioic acid, the counterpart of 2-mercapto-succinic acid diethylester formed during hydrolysis. A similar phenomenon has been observed by Miyamoto and Yamamoto (1977). Their experimental results indicate that the hydrolysis of the unstable phosphorus oxythionate intermediates might take place in the 3-chlorobenzoic acid oxidation of 0,0 diethyl-s-(4-chlorophenyl)phosphorodithioate. The hydrolysis of

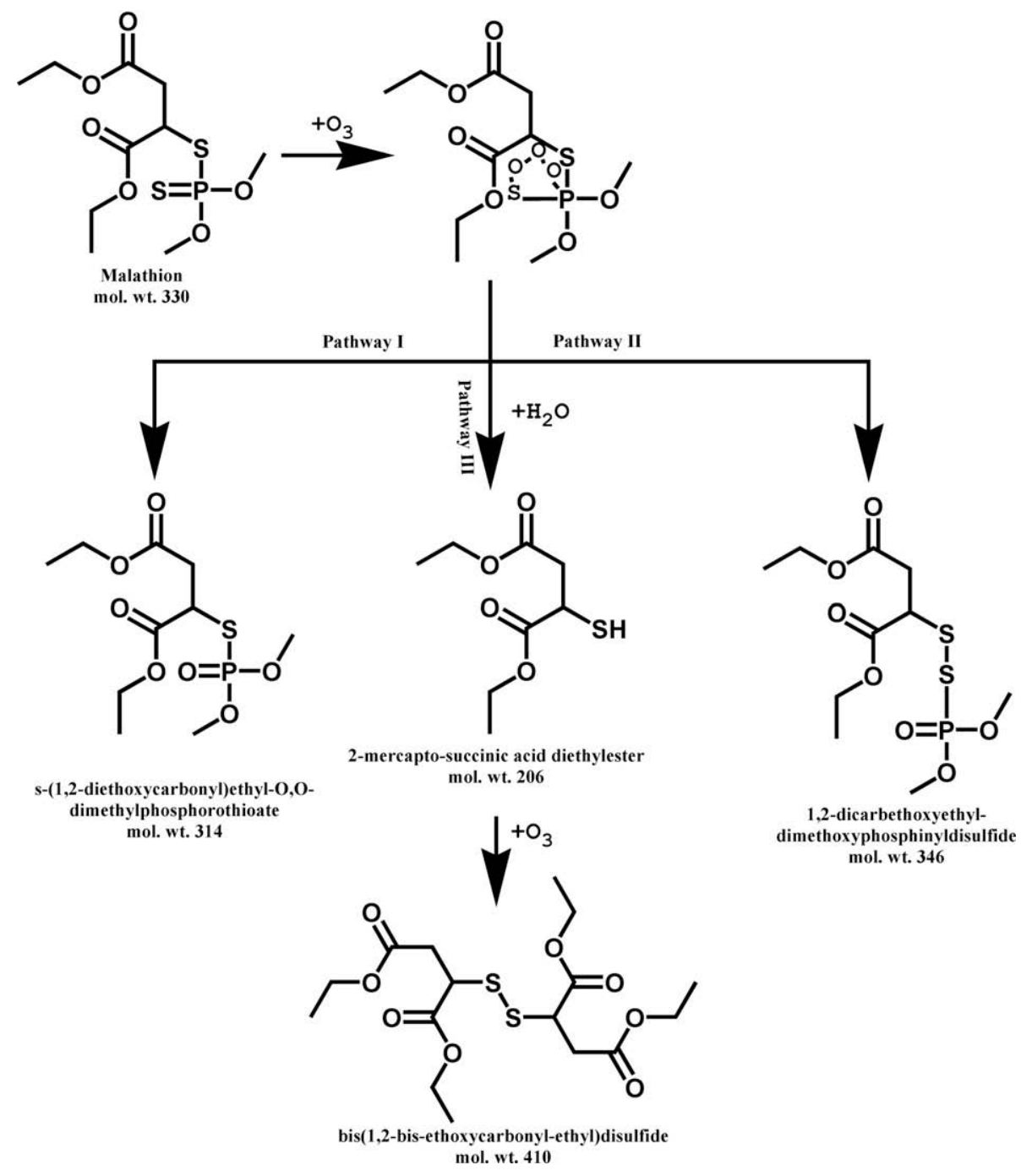

Fig. 5. Proposed pathways of the heterogeneous ozonation of particulate malathion. 
the unstable phosphorus oxythionate intermediates results in the formation of thiol compounds, which forms bis(4-chlorophenyl)disulfide by further oxidation. The signal of bis(1,2-bis-ethoxycarbonyl-ethyl)disulfide is observed enhanced greatly under the extremely wet condition, which might be an evidence for Pathway III of the malathion ozonation. Since the formation of bis(1,2-bis-ethoxycarbonyl-ethyl)disulfide needs the collision of two 2-mercapto-succinic acid diethylester molecules, we speculate that there may be a certain amount of gas-phase 2-mercapto-succinic acid diethylester formed in the ozonation of malathion vapor (vapor pressure $=1.78 \times 10^{-4} \mathrm{~Pa}$ at $25^{\circ} \mathrm{C}$ ). The phenomenon observed in this experiment is also consistent with the results by Warren et al. (2009) which indicate that the water vapor may react with the Crigee intermediate in the ozonation of gas-phase cyclohexane to form hydrolysis products.

Compared with malathion, the pathway of the ozonation of chlorpyrifos is very simple. Chlorpyrifos oxon is the sole product observed in the ozonation of chlorpyrifos, which corresponds to the product formed in the pathway of the sulfur loss.

The atmospheric lifetimes of malathion and chlorpyrifos particles due to reaction with ozone can be roughly estimated based on the decay rates of the reactants and the growth rates of products derived from the time-dependent mass spectrometric signals obtained in the experiment. The decay rate of malathion particles and the growth rate of malaoxon (the main ozonation product) measured are $\sim 8.0 \times 10^{-19} \mathrm{~cm}^{3}$ molecule ${ }^{-1} \mathrm{~s}^{-1}$. Using the formula of $\tau_{\mathrm{O} 3}=1 /\left(\mathrm{k}_{\mathrm{O} 3} \times\left[\mathrm{O}_{3}\right]\right)$ and $\left[\mathrm{O}_{3}\right]=7 \times 10^{11}$ molecule $\mathrm{cm}^{-3}$ (Logan, 1985), the atmospheric lifetimes of malathion particles towards ozone reaction is $\sim 18 \mathrm{~d}$. The decay rate of chlorpyrifos particles and the growth rate of chlorpyrifos oxon (the main ozonation product) measured are $\sim 1.5 \times 10^{-18} \mathrm{~cm}^{3}$ molecule ${ }^{-1} \mathrm{~s}^{-1}$, which corresponds to an atmospheric lifetime of $\sim 9 \mathrm{~d}$. Compared with the atmospheric lifetimes of the gas-phase 0,O,S-trimethylphosphorodithioate ( $83 \mathrm{~d}$, the analogue of malathion) and the 0,0,O-trimethylthiophosphate ( $55 \mathrm{~d}$, the analogue of chlorpyrifos) due to reaction with ozone (Goodman et al., 1988), the atmospheric lifetime of malathion and chlorpyrifos particles due to reaction with ozone are relatively shorter. The discrepancies between these atmospheric lifetimes may result from the different molecular structures of the analogues or the different circumstances of the reactions.

During the experiments, the high concentrations of ozone and organosphosphorous pesticide particles are applied for producing the signals of ozonation products strong enough to meet the sensitivity of the VUV-ATOFMS. These experimental conditions are apparently different from those in the atmosphere, which may lead to some discrepancies in the product yields and the ozonation pathways of organosphosphorous pesticides particles. Nevertheless, these experimental data provide a useful reference for understanding the ozonation mechanism of organosphosphorous pesticide particles under realistic atmospheric conditions.

\section{Acknowledgments}

This work was funded by the National Natural Science Foundation of China (Grant No. 20673138) and Creative Research Groups of China (Grant No. 50921064).

\section{References}

Adeniji, S.A., Kerr, J.A., Williams, M.R., 1981. Rate constants for ozone-alkene reactions under atmospheric conditions. Int. J. Chem. Kinet. 13, 209-217.

Aston, L.S., Seiber, J.N., 1997. Fate of summertime airborne organophosphate pesticide residues in the Sierra Nevada Mountains. J. Environ. Qual. 26, 14831492.

Atkinson, R., Carter, W.P.L., 1984. Kinetics and mechanisms of the gas-phase reactions of ozone with organic-compounds under atmospheric conditions. Chem. Rev. 84, 437-470.
Atkinson, R., Guicherit, R., Hites, R.A., Palm, W.U., Seiber, J.N., de Voogt, P., 1999. Transformations of pesticides in the atmosphere: a state of the art. Workshop on Fate of Pesticides in the Atmosphere Implications for Risk Assessment. Kluwer Academic Publ., Driebergen, Netherlands. pp. 219-243.

Bavcon, M., Trebse, P., Zupancic-Kralj, L., 2003. Investigations of the determination and transformations of diazinon and malathion under environmental conditions using gas chromatography coupled with a flame ionisation detector. Chemosphere 50, 595-601.

Bavcon Kralj, M., Franko, M., Trebse, P., 2007. Photodegradation of organophosphorus insecticides - investigations of products and their toxicity using gas chromatography-mass spectrometry and AChE-thermal lens spectrometric bioassay. Chemosphere 67, 99-107.

Bedos, C., Cellier, P., Calvet, R., Barriuso, E., 2002. Occurrence of pesticides in the atmosphere in France. Agronomie 22, 35-49.

Bellet, E.M., Casida, J.E., 1974. Products of peracid oxidation of organothiophosphorus compounds. J. Agric. Food Chem. 22, 207-211.

Berkelhammer, G., Dauterman, W.C., Obrien, R.D., 1963. Conversion of phosphorothionates to their oxygen analogs with dinitrogen tetroxide. J. Agric. Food Chem. 11, 307-308.

Brown, M.A., Petreas, M.X., Okamoto, H.S., Mischke, T.M., Stephens, R.D., 1993. Monitoring of malathion and its impurities and environmental transformation products on surfaces and in air following an aerial application. Environ. Sci. Technol. 27, 388-397.

Duirk, S.E., Tarr, J.C., Collette, T.W., 2008. Chlorpyrifos transformation by aqueous chlorine in the presence of bromide and natural organic matter. J. Agric. Food Chem. 56, 1328-1335.

FinlaysonPitts, B.J., Pitts, J.N., 1997. Tropospheric air pollution: ozone, airborne toxics, polycyclic aromatic hydrocarbons, and particles. Science 276, 10451052.

Gao, S.K., Zhang, Y., Meng, J.M., Shu, J.N., 2009. Online investigations on ozonation products of pyrene and benz[a]anthracene particles with a vacuum ultraviolet photoionization aerosol time of flight mass spectrometer. Atmos. Environ. 43, 3319-3325.

Gil, Y., Sinfort, C., 2005. Emission of pesticides to the air during sprayer application: a bibliographic review. Atmos. Environ. 39, 5183-5193.

Glotfelty, D.E., Seiber, J.N., Liljedahl, L.A., 1987. Pesticides in fog. Nature 325, 602605.

Goel, A., McConnell, L.L., Torrents, A., 2007. Determination of vapor pressuretemperature relationships of current-use pesticides and transformation products. J. Environ. Sci. Health B 42, 343-349.

Goodman, M.A., Aschmann, S.M., Atkinson, R., Winer, A.M., 1988. Kinetics of the atmospherically important gas-phase reactions of a series of trimethyl phosphorothioates. Arch. Environ. Contom. Toxicol. 17, 281-288.

Ikehata, K., El-Din, M.G., 2005. Aqueous pesticide degradation by ozonation and ozone-based advanced oxidation processes: a review (part I). Ozone-Sci. Eng. 27, 83-114.

Jamal, G.A., 1997. Neurological syndromes of organophosphorus compounds. Adverse Drug React. T. 16, 133-170.

Kralj, M.B., Cernigoj, U., Franko, M., Trebse, P., 2007. Comparison of photocatalysis and photolysis of malathion, isomalathion, malaoxon, and commercial malathion - products and toxicity studies. Water Res. 41, 4504-4514.

Kwamena, N.O.A., Staikova, M.G., Donaldson, D.J., George, I.J., Abbatt, J.P.D., 2007. Role of the aerosol substrate in the heterogeneous ozonation reactions of surface-bound PAHs. J. Phys. Chem. A 111, 11050-11058.

Laplanche, A., Martin, G., Tonnard, F., 1984. Ozonation schemes of organophosphorus pesticides application in drinking-water treatment. OzoneSci. Eng. 6, 207-219.

LeNoir, J.S., McConnell, L.L., Fellers, G.M., Cahill, T.M., Seiber, J.N., 1999. Summertime transport of current-use pesticides from California's Central Valley to the Sierra Nevada Mountain Range, USA. Environ. Toxicol. Chem. 18, 2715-2722.

Lide, D.R., Milne, G.W.A., 1994. Handbook of Data on Common Organic Compounds. CRC Press.

Liu, B., McConnell, L.L., Torrents, A., 2001. Hydrolysis of chlorpyrifos in natural waters of the Chesapeake Bay. Chemosphere 44, 1315-1323.

Ljubic, I., Sabljic, A., 2002. Theoretical study of the mechanism and kinetics of gasphase ozone additions to ethene, fluoroethene, and chloroethene: a multireference approach. J. Phys. Chem. A 106, 4745-4757.

Logan, J.A., 1985. Tropospheric ozone-seasonal behavior, trends, and anthropogenic influence. J. Geophys. Res. - Atmos. 90, 10463-10482.

Luo, Y.Z., Zhang, M.H., 2009. Multimedia transport and risk assessment of organophosphate pesticides and a case study in the northern San Joaquin Valley of California. Chemosphere 75, 969-978.

Meng, J.W., Yang, B., Zhang, Y., Shu, X., Shu, J.N., 2009. Ozonation of trifluralin particles: an experimental investigation with a vacuum ultraviolet photoionization aerosol time-of-flight mass spectrometer. J. Hazard. Mater. 172, 390-394.

Miles, C.J., Takashima, S., 1991. Fate of malathion and O,O,S-trimethyl phosphorothioate by-product in Hawaiian soil and water. Arch. Environ. Contom. Toxicol. 20, 325-329.

Miyamoto, T., Yamamoto, I., 1977. Mechanism of phosphinyl disulfide formation from a phosphorodithioate ester. J. Pestic. Sci. 2, 303-310.

Mulla, M.S., Mian, L.S., Kawecki, J.A., 1981. Distribution, transport, and fate of the insecticides malathion and parathion in the environment. Residue Rev.81,1-172.

Ohashi, N., Tsuchiya, Y., Sasano, H., Hamada, A., 1994. Ozonation products of organophosphorous pesticides in water. Jpn. J. Toxicol. Environ. Health 40, 185192. 
Pehkonen, S.O., Zhang, Q., 2002. The degradation of organophosphorus pesticides in natural waters: a critical review. Crit. Rev. Environ. Sci. Technol. 32, 17-72.

Racke, K.D., 1993. Environmental fate of chlorpyrifos. Rev. Environ. Contam. Toxicol. $131,1-150$.

Reynolds, G., Graham, N., Perry, R., Rice, R.G., 1989. Aqueous ozonation of pesticides - a review. Ozone-Sci. Eng. 11, 339-382.

Ryan, D.L., Fukuto, T.R., 1985. The effect of impurities on the toxicokinetics of malathion in rats. Pestic. Biochem. Phys. 23, 413-424.

Sabljic, A., Peijnenburg, W., 2001. Recommendations on modelling lifetime and degradability of organic compounds in air, soil and water systems. Pure Appl. Chem. 73, 1331-1348.

Shu, J.N., Gao, S.K., Li, Y., 2008. A VUV photoionization aerosol time-of-flight mass spectrometer with a RF-powered VUV lamp for laboratory-based organic aerosol measurements. Aerosol Sci. Technol. 42, 110-113.

Tomlin, C.D.S, 2003. The Pesticide Manual. 13th ed. British Crop Protection Council, Alton, Hampshire, UK.

Tomlin, C.D.S., 2006. The Pesticide Manual: A World Compendium. 14th ed.. British Crop Protection Council Publications, Farnham, UK.

Van den Berg, F., Kubiak, R., Benjey, W.G., Majewski, M.S., Yates, S.R., Reeves, G.L., Smelt, J.H., van der Linden, A.M.A., 1999. Emission of Pesticides into the Air. Workshop on Fate of Pesticides in the Atmosphere Implications for Risk Assessment. Kluwer Academic Publ., Driebergen, Netherlands. pp. 195218.
Van Dijk, H.F.G., Guicherit, R., 1999. Atmospheric Dispersion of Current-use Pesticides: A Review of the Evidence from Monitoring Studies. Workshop on Fate of Pesticides in the Atmosphere Implications for Risk Assessment. Kluwer Academic Publ., Driebergen, Netherlands. pp. 21-70.

Van Pul, W.AJ. Bidleman, T.F., Brorstrom-Lunden, E, Builtjes, PJ.H., Dutchak, S. Duyzer, J.H., Gryning, S.E., Jones, K.C., van Dijk, H.F.G., van Jaarsveld, J.A., 1999 Atmospheric Transport and Deposition of Pesticides: An Assessment of Current Knowledge. Workshop on Fate of Pesticides in the Atmosphere Implications for Risk Assessment. Kluwer Academic Publ., Driebergen, Netherlands. pp. 245256.

Vincent, P., Herv, F., Pierre, M., 1997. Atmospheric transport of pesticides II field study. Toxicol. Environ. Chem. 58, 1-15.

Vingarzan, R., 2004. A review of surface ozone background levels and trends. Atmos. Environ. 38, 3431-3442.

Warren, B., Malloy, Q.G.J., Yee, L.D., Cocker, D.R., 2009. Secondary organic aeroso formation from cyclohexene ozonolysis in the presence of water vapor and dissolved salts. Atmos. Environ. 43, 1789-1795.

Wu, J.G., Laird, D.A., 2003. Abiotic transformation of chlorpyrifos to chlorpyrifos oxon in chlorinated water. Environ. Toxicol. Chem. 22, 261-264.

Zhao, X.Z., Hwang, H.M., 2009. A study of the degradation of organophosphorus pesticides in river waters and the identification of their degradation products by chromatography coupled with mass spectrometry. Arch. Environ. Contom. Toxicol. 56, 646-653. 